\title{
Neuroradiological imaging features of infratentorial cranial fossa tumors in a child
}

\section{Muhammad Yunus Amran, Meryana Pauline, Andi Kurnia Bintang, Muhammad Akbar}

\section{CASE REPORT}

An 11-year-old boy was admitted to our hospital with the chief complaint of a generalized tonic seizure which was preceded by projectile vomiting, six hours prior to his admission. There was no previous history of such complaint. The patient's right arm and right leg were rigid and extended while his left arm and left leg were rigid and flexed. Five years before admission, the patient had complained of chronic headaches. One year before admission, the patient had complained of blurred vision in his left eye followed by the same complaint in the

\begin{abstract}
Muhammad Yunus Amran ${ }^{1,2}$, Meryana Pauline ${ }^{3}$, Andi Kurnia Bintang ${ }^{4}$, Muhammad Akbar ${ }^{5}$

Affiliations: ${ }^{1} \mathrm{MD}, \mathrm{Ph} . \mathrm{D}, \quad$ Candidate, Department of Bacteriology, Laboratory of Division Basic Medical Science and Molecular, Graduate School of Medical Sciences and School of Medicine, Kyushu University, Fukuoka, Japan; ${ }^{2} \mathrm{MD}$, Clinical Assistant Professor and Lecturer, Hasanuddin University Hospital, Department of Neurology, Faculty of Medicine, Hasanuddin University, Makassar, South Sulawesi, Indonesia; ${ }^{3} \mathrm{MD}$, Clinical Assistant Professor, Hasanuddin University Hospital, Department of Neurology, Faculty of Medicine, Hasanuddin University, Makassar, South Sulawesi, Indonesia; ${ }^{4} \mathrm{MD}$, Clinical Associate Professor and Lecturer, Hasanuddin University Hospital, Department of Neurology, Faculty of Medicine, Hasanuddin University, Makassar, South Sulawesi, Indonesia; ${ }^{5} \mathrm{MD}$, Ph.D, Professor and Head of Department, Hasanuddin University Hospital, Department of Neurology, Faculty of Medicine, Hasanuddin University, Makassar, South Sulawesi, Indonesia

Corresponding Author: Muhammad Yunus Amran, MD, Department of Neurology, Hasanuddin University Hospital, Faculty of Medicine, Hasanuddin University, Jl. Perintis Kemerdekaan KM 11 (Pintu II UNHAS), Makassar, 90245 South Sulawesi, Indonesia; Ph: +62-411-585560; Fax No: +62-411-582837; Office Email: saraf_mks@yahoo.com; Email:yunus_amran98@yahoo.com
\end{abstract}

Received: 07 June 2012

Accepted: 29 August 2012

Published: 01 January 2013 right eye. The blurred vision became progressively chronic, accompanied by diplopia. Three months before presenting to us, he demonstrated truncal ataxia. The patient had no problems with either urination or defecation. There was no history of fever, growth disorders or developmental disorders. Neurological examination showed neck stiffness. His pupils showed isochore mydriasis with decreased light reflexes and papilledema; the patient's visual acuity in both left and right eye was $1 / 300$ with convergent strabismus in the left eye, and left peripheral facial paresis. On motor examination, we found dysmetria and disdiadochokinesia in the extremities of the left side as well as hypotonia on both the sides. Sensory and autonomic functions were within normal limits. Routine and blood chemistry analyses revealed the following results: Hemoglobin $12.5 \mathrm{~g} / \mathrm{dL}$, hematocrit $38.3 \%$, WBC counts $8 \times 10^{3} / \mathrm{mm}^{3}$, platelet count $3.13 \times 10^{5} / \mathrm{mm}^{3}$, blood sugar (random) $156 \mathrm{mg} / \mathrm{dL}$, SGOT $20 \mathrm{IU} / \mathrm{L}$, SGPT 53 $\mathrm{IU} / \mathrm{L}$, urea $15.53 \mathrm{mg} / \mathrm{dL}$, creatinine $0.32 \mathrm{mg} / \mathrm{dL}$, sodium $135 \mathrm{mmol} / \mathrm{dL}$, potassium $4.2 \mathrm{mmol} / \mathrm{dL}$ and chloride 101 $\mathrm{mmol} / \mathrm{dL}$. Axial head computed tomography (CT) scans of both noncontrast and contrast (with administration of intravenous gadolinium (Gd-DOTA)) were performed. The CT scan revealed a mass in the infratentorial cranial fossa which suggested a medulloblastoma with a differential diagnosis of an ependymoma (Figure 1A-B). After post-contrast the mass density was enhanced. This result suggested an ependymoma with non-communicating hydrocephalus (Figure $1 \mathrm{C}-\mathrm{D}$ ). The patient was scheduled to undergo ventriculoperitoneal (VP) shunting to relieve the increased intracranial pressure due to mass effect from the tumor in the fourth ventricle. Subsequently, an magnetic resonance imaging (MRI) scan was performed with and without administration of intravenous GdDOTA. The MRI scan showed a round lesion with a clear border, irregular edges, hypo intensity in the axial and sagittal T1-weighted images, and hypo intensity in the T1WI noncontrast images, (Figure $2 \mathrm{~A}-\mathrm{B}$ ) as well as hyper intensity in the T1WI post-contrast images (Figure 2C-D). Simultaneously, T2WI revealed hyper intensity, heterogeneous density and ring/rim enhancement, which is consistant with the description 


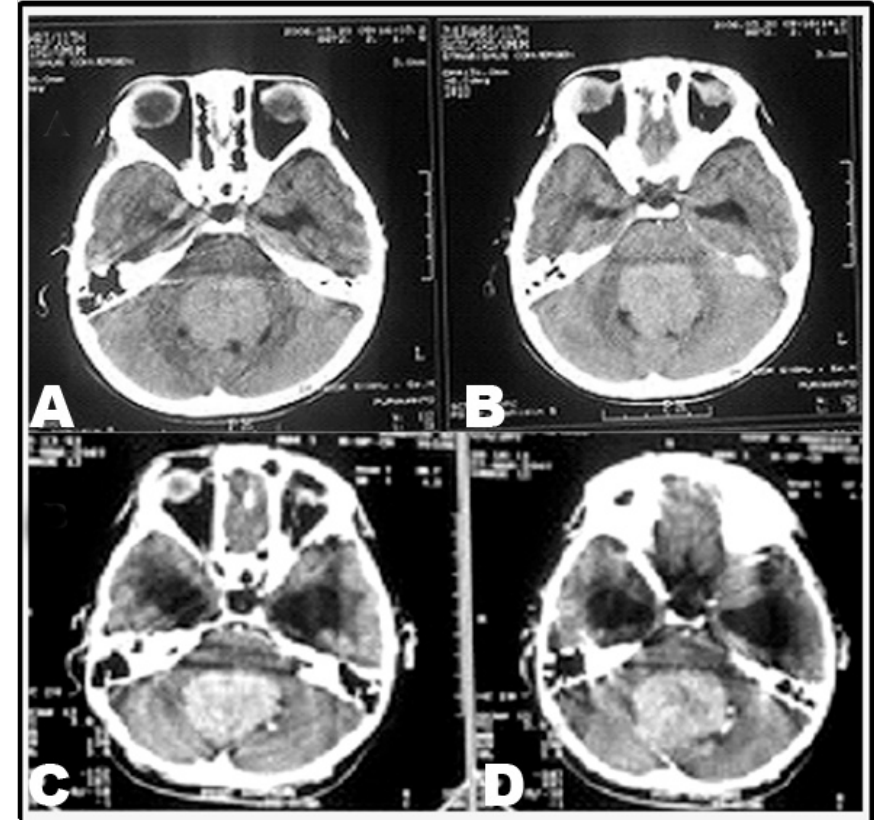

Figure 1: Axial head computed tomography scan images (A, B) Noncontrast showing, a lesion with hyper density and calcified spots, demarcated, with a density of $44,2 \mathrm{Hu}$ in the infra tentorial fossa pressing on the anterior aspect of fourth ventricle causing dilatation of the lateral and third ventricles and, (C, D) Post-contrast with intravenous gadolinium (GdDOTA) showing, a mass in the infra tentorial fossa, which is suspected to have arisen from the fourth ventricle. The mass is lobulated and round shaped, demarcated with irregular edges and enhanced density of $54.7 \mathrm{Hu}$ post-contrast, causing dilatation of the lateral and third ventricle.

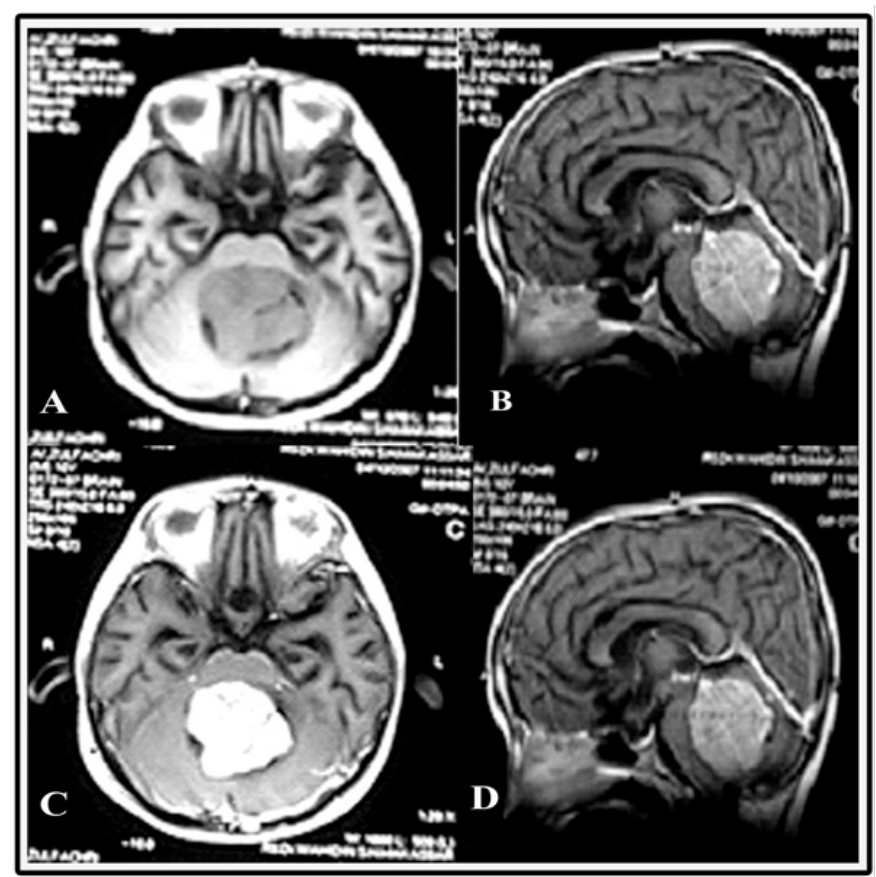

Figure 2: (A) Axial and (B) Sagittal head, Magnetic resonance imaging (MRI) scan images (noncontrast) post VP-shunting showing a round lesion with clear borders, irregular edges, size $4.87 \times 5.43 \mathrm{~cm}$ in the area of the fourth ventricle and mass with hypo intensity on T1WI; (C) Axial and (D) Sagittal head MRI scan images (with contrast) post VP-shunting showing a round lesion with clear borders, irregular edges, size $4.87 \times 5.43$ $\mathrm{cm}$ in the area of the fourth ventricle and mass with hyper intensity on T1WI.

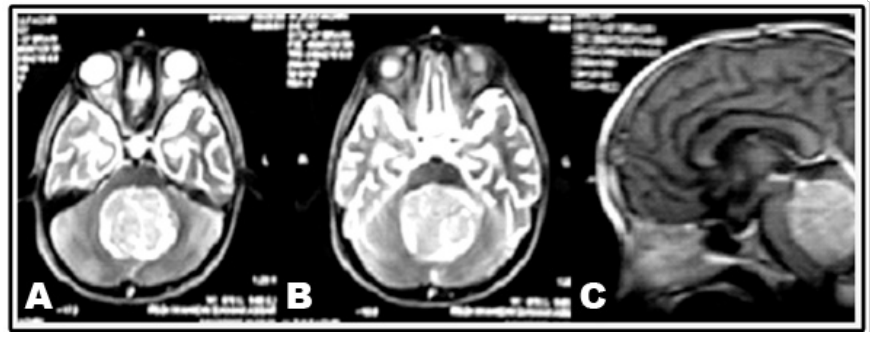

Figure 3: (A, B) Axial head magnetic resonance imaging scan T2-weighted image; post VP-shunting, showing a mass with hyper intensity and heterogeneous density on T2WI signal, especially at the edge (ring/rim enhancement) which is consistant with the description of an ependymoma, (C) Sagittal head MRI scann T2-weighted image, post VPshunting, also showing a mass with hyper intensity and heterogeneous density on T2WI signal.

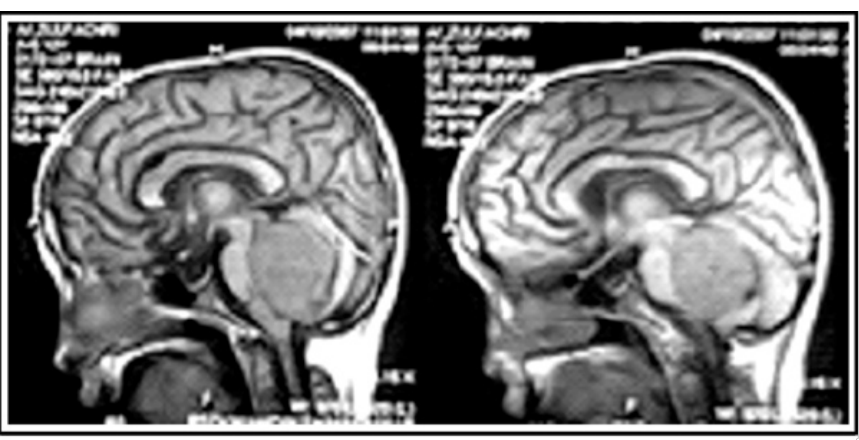

Figure 4: Sagittal head FLAIR-MRI images post VP-shunting, showing an intermediate flair signal relative to both gray and white matter.

of an ependymoma (Figure $3 \mathrm{~A}-\mathrm{C}$ ) Fluid-attenuated inversion recovery (FLAIR) MRI further showed the mass with hyper intensity and a heterogeneous signal density (Figure 4). After VP-shunting, the headache was relieved and no more seizures occurred, after which a tentative plan for tumour resection followed by radiotherapy was made. Unfortunately, the patient was discharged against medical advice from the hospital before the surgical procedure could be carried out.

\section{DISCUSSION}

Ependymoma is a rare tumor derived from the neuroepithelia, constituting about $3-9 \%$ of all central nervous system (CNS) tumors. In children, approximately two-thirds of such tumors occur in the infratentorial compartment while in adults the distribution is normally supratentorial. Ependymomas can be located either intracranially or intraspinally. Intracranial ependymomas occur more commonly in children, while intraspinal ependymomas predominate in adults. Sixty percent of tumors are located in the fourth ventricle of the infratentorial cranial fossa, which develop from the floor of the ventricle and may further extend into the foramen of Luschka and Magendie. Here we reported a case of ependymoma in the infratentorial 
cranial fossa with a differential diagnosis of medulloblastoma on head CT scan and MRI scan.

In 1863, Virchow was the first to properly identify an ependymoma derived from ependymal cells [1]. This was followed by Bailey et al. in 1926, who described an ependymoma and an ependymoblastoma, which have been considered the most primitive tumors of the nervous system. This tumor arises from the medullary epithelial plate $[2,3]$. Recently, researchers have proposed that radial glial cells may be the candidate stem cells of this tumor $[4,5]$. The annual incidence in the countries of Central and South America as well as Asia is less than two per million in childhood [6]. In North America, Oceania and most of Europe, between 2-4 cases per million was reported, while in Denmark, Sweden, Finland, former East Germany and Slovenia, at least four cases per million are reported. Recently, McGuire et al. reported a comparison of the mean age of tumor incidence by tumor site in 237 children. Children with $5 \pm 0.4$ years of age had only $4.2-5.9 \%$ of tumor located infratentorially while those of $12.2 \pm 0.9$ years of age had $10.6-13.7 \%$ of tumor located in spinal column [7]. This indicated that the tumors would most likely be located in the spinal column when diagnosed in children with the average of age around 11 years; nevertheless, herein we have reported an 11-year-old child with a tumor located in the infratentorial space. According to WHO classification, ependymomas are classified into three categories:

(i) WHO grade I: subependymoma, myxopapillary ependymoma;

(ii) WHO grade II: classic ependymoma (with the variation of cellular, papillary, clear cell, and fibrillary or tanycytic);

iii) WHO grade III: anaplastic ependymoma [8]. The symptoms of ependymomas depend on the tumor location, rate of tumor growth, etc.

In our patient the chief complaint was a generalized tonic seizure, followed by several symptoms which are associated with the location of the tumor in the infratentorial cranial fossa, such as vomiting, headaches, double vision and unsteadiness. Fundoscopic examination and neuroradiology imaging indicated an increase in intracranial pressure. Ependymomas are the third most common pediatric brain tumor (10.1\%) after astrocytomas (47.3\%) and medulloblastoma (16.3\%) [9]. In the above list, atypical teratoid-rhabdoid tumor (ATRT) should be considered as well. It is very difficult to differentiate among these tumors, especially between a medulloblastoma and an ependymoma since both normally present as midline tumors, whereas astrocytoma and ATRT are generally eccentric. In order to distinguish between these tumors, additional examinations (CT scan and MRI) need to be performed. Based on the results from a non-contrast head CT scan, we made an initial diagnosis of a medulloblastoma with a differential diagnosis of ependymoma, although after an intravenous injection with contrast the results suggested that what the patient had was in fact an ependymoma. Moreover, head MRI scans revealed the ring/rim enhancement that is very typical for ependymomas. With regards to therapy, the symptoms should be relieved by the use of anticonvulsants and anti-edema agents. VP-shunting must be done to release the increase in intracranial pressure, followed by tumour resection and radiotherapy. All of this is essential to improve the patient's outcome [10].

\section{CONCLUSION}

Detailed history and physical examinations are very important to diagnose an infratentorial cranial fossa occupying lesion. Radiological imaging by computed tomography scan and magnetic resonance imaging scan is essential to support the diagnosis of ependymoma and to distinguish it from a medulloblastoma. Moreover, improved patient outcome requires total tumor resection whenever possible, followed by radiotherapy.

$* * * * * * * * *$

Amran MY, Pauline M, Bintang AK, Akbar M. Neuroradiological imaging features of infratentorial cranial fossa tumors in a child. International Journal of Case Reports and Images 2013;4(1):76-79.

$* * * * * * * * *$

doi:10.5348/ijcri-2013-01-264-CI-18

$$
* * * * * * * * *
$$

\section{Author Contributions}

Muhammad Yunus Amran - Substantial contributions to conception and design, Acquisition of data, Analysis and interpretation of data, Drafting the article, Revising it critically for important intellectual content, Final approval of the version to be published

Meryana Pauline - Substantial contributions to conception and design, Acquisition of data, Analysis and interpretation of data, Drafting the article, Revising it critically for important intellectual content, Final approval of the version to be published

Andi Kurnia Bintang - Substantial contributions to conception and design, Acquisition of data, Analysis and interpretation of data, Drafting the article, Revising it critically for important intellectual content, Final approval of the version to be published

Muhammad Akbar - Substantial contributions to conception and design, Acquisition of data, Analysis and interpretation of data, Drafting the article, Revising it critically for important intellectual content, Final approval of the version to be published

\section{Guarantor}

The corresponding author is the guarantor of submission.

\section{Conflict of Interest}

Authors declare no conflict of interest. 


\section{Copyright}

(C) Muhammad Yunus Amran et al. 2013; This article is distributed under the terms of Creative Commons Attribution 3.0 License which permits unrestricted use, distribution and reproduction in any means provided the original authors and original publisher are properly credited. (Please see www.ijcasereportsandimages.com /copyright-policy.php for more information.)

\section{REFERENCES}

1. Virchow R. Die krankhaften Geschwülste. Hirschwald. 1863/1865. Berlin.

2. Bailey P, Cushing H. A classification of the tumors of the glioma group on a histogenetic basis with a correlated study of prognosis. JP Lippincott 1926. Philadelphia.

3. Bailey P. A study of tumors arising from ependymal cells. Arch Neurol Psychiatry 1924;11:1-27.

4. Taylor MD, Poppleton H, Fuller C, et al. Radial glia cells are candidate stem cells of ependymoma. Cancer Cell 2005;8(4):323-35.
5. Poppleton H, Gilbertson RJ. Stem cells of ependymoma. Br J Cancer 2007 Jan 15;96(1):6-10.

6. Parkin DM, Kramarova E, Draper JG, et al. International incidence of childhood cancer, Vol. II. IARC Scientific Pub 1998;(144):1-391.

7. McGuire CS, Sainani KL, Fisher PG. Incidence patterns for ependymoma: a surveillance, epidemiology, and end results study. J Neurosurg 2009;110(4):725-9.

8. Louis DN, Ohgaki H, Wiestler OD, et al. The 2007 WHO classification of tumours of the central nervous system. Acta Neuropathol 2007;114(2):97-109.

9. Rickert $\mathrm{CH}$, Paulus W. Epidemiology of central nervous system tumors in childhood and adolescence based on the new WHO classification. Childs Nerv Syst 2001;17(9):503-11.

10. Chan MD, McMullen KP. Multidisciplinary management of intracranial ependymoma. Curr Probl Cancer 2012;36(1):6-19..
Access full text article on other devices

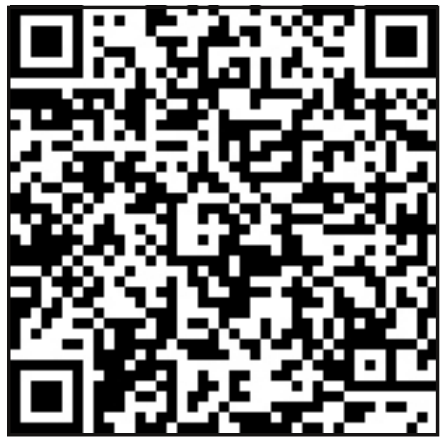

Access PDF of article on other devices

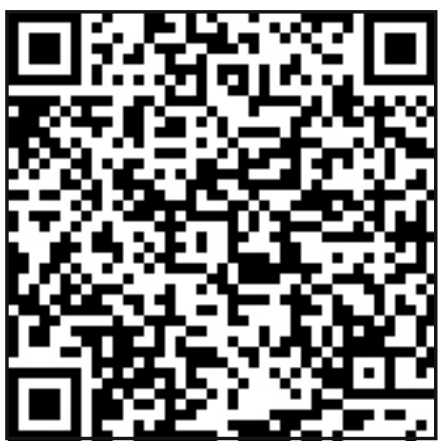

